\title{
Interleukin (IL)-25 suppresses IL-22-induced osteoclastogenesis in rheumatoid arthritis via STAT3 and p38 MAPK//kBa pathway
}

Hong Ki Min', Ji-Yeon Won², Bo-Mi Kim³ ${ }^{3}$ Kyung-Ann Lee ${ }^{4}$, Seoung-Joon Lee ${ }^{5}$, Sang-Heon Lee ${ }^{6}$, Hae-Rim Kim ${ }^{6}$ and Kyoung-Woon $\mathrm{Kim}^{2 *}$

\begin{abstract}
Background: The present study aimed to evaluate the suppressive role of interleukin (IL)-25 in IL-22-induced osteoclastogenesis and receptor activator of nuclear factor $\mathrm{KB}$ ligand (RANKL) expression in rheumatoid arthritis (RA).

Methods: Serum from patients with RA and osteoarthritis (OA), and healthy controls, and synovial fluid from patients with RA and OA were collected, and the levels of IL-22 and IL-25 were measured. RA and OA synovial tissues were stained against IL-25. Fibroblast-like synoviocytes (FLSs) of patients with RA were cultured with IL-22, in the presence or absence of IL-25, and RANKL expression was measured by real-time PCR and enzyme-linked immunosorbent assay (ELISA). Human peripheral blood monocytes were cultured under IL-22/RANKL + M-CSF, with or without IL-25, and tartrate-resistant acid phosphatase (TRAP)-positive cells and osteoclast-related markers were investigated to determine osteoclastogenesis.

Results: Serum and synovial IL-25 levels in RA were upregulated compared to those in OA and healthy control, and elevated expression of IL-25 in RA synovial tissue was re-confirmed. IL-25 and IL-22 levels showed significant correlation in serum and synovial fluid. Pre-treatment of FLS with IL-25 reduced IL-22-induced RANKL expression at the RNA level. The suppressive effects of IL-25 were confirmed to occur through the STAT3 and p38 MAPK/KBa pathways. IL-25 reduced osteoclast differentiation and suppressed the expression of osteoclast-related markers.

Conclusion: In the current study, we demonstrated the regulatory effect of IL-25 on IL-22-induced osteoclastogenesis. Therapeutic approach involving augmentation of IL-25 regulatory response may serve as a novel treatment option for RA, especially by suppressing osteoclastogenesis.
\end{abstract}

Keywords: Rheumatoid arthritis, Osteoclastogenesis, IL-22, IL-25

\footnotetext{
*Correspondence: woon6002@gmail.com

${ }^{2}$ R\&D Center, Oncolnsight, 1022, Gangnam AceTower, 174-10, Jagok-ro, Gangnam-gu, Seoul 06373, Republic of Korea

Full list of author information is available at the end of the article
}

(c) The Author(s). 2020 Open Access This article is licensed under a Creative Commons Attribution 4.0 International License, which permits use, sharing, adaptation, distribution and reproduction in any medium or format, as long as you give appropriate credit to the original author(s) and the source, provide a link to the Creative Commons licence, and indicate if changes were made. The images or other third party material in this article are included in the article's Creative Commons licence, unless indicated otherwise in a credit line to the material. If material is not included in the article's Creative Commons licence and your intended use is not permitted by statutory regulation or exceeds the permitted use, you will need to obtain permission directly from the copyright holder. To view a copy of this licence, visit http://creativecommons.org/licenses/by/4.0/. The Creative Commons Public Domain Dedication waiver (http://creativecommons.org/publicdomain/zero/1.0/) applies to the data made available in this article, unless otherwise stated in a credit line to the data. 


\section{Background}

Rheumatoid arthritis (RA) is an autoimmune-mediated systemic arthritis. Treatment of RA aims to achieve the following: attainment of low disease activity or remission at the earliest, cessation of structural damage of the affected joints, and prevention of RA-related comorbidities [1]. Pannus is a typical synovial hyperplasia of RA, which can invade into the adjacent articular structure, cartilage, and subchondral bone, thereby inducing erosive joint destruction and deformities [2]. Prevention of such destructive bone erosion is important, primarily due to their irreversible nature. Activation of osteoclasts and secretion of proteases are the main mechanisms underlying cartilage and bone erosion [2]. Maturation and activation of osteoclasts require interaction between receptor activator of nuclear factor $\kappa \mathrm{B}$ (RANK) and RANK ligand (RANKL). RANKL can be produced by various cells, although fibroblast-like synoviocyte (FLS), the main cellular component of pannus, is the major source of RANKL in RA synovium [3]. Suppression of RANKL is one of the treatment goals in RA to reduce osteoclastogenesis and eventually cease the irreversible articular damage in RA.

Many pro-inflammatory cytokines, such as tumor necrosis factor (TNF)- $\alpha$, interleukin (IL)-1 $\beta$, IL-6, and IL$17 \mathrm{~A}$, induce inflammatory processes and bone destruction in RA pathogenesis [4]. Patients with RA, who do not respond to or tolerate conventional synthetic disease-modifying antirheumatic drugs (DMARDs), can use biologic DMARDs instead, which target specific proinflammatory cytokines or cell surface molecules [4]. These biologic DMARDs have caused a marked improvement of treatment strategy and clinical remission in RA, although some patients still fail to respond to them, and joint destruction continues to progress. IL-22, a member of the IL-10 superfamily, has recently emerged as a pathological cytokine in animal models of RA [5, 6]. IL-22-producing cluster of differentiation (CD) $4^{+} \mathrm{T}$ cell (Th22) population has been found to be elevated in patients with RA compared to that in healthy controls, and it is also correlated with the disease activity score [7]. Furthermore, IL-22 has been reported to promote FLS proliferation and RANKL expression in FLS, and IL-22-pre-treated FLSs can upregulate osteoclastogenesis $[8,9]$. These findings propose a potential therapeutic approach in RA by suppressing IL-22.

IL-25, also called IL-17E, is one of the IL-17 superfamily cytokines, composed of six subtypes, IL-17A to IL$17 \mathrm{~F}$; they bind to the corresponding receptor, IL-17 receptor, which in turn is composed of five members, IL17RA to IL-17RE [10]. Although IL-17 family cytokines share approximately $50 \%$ of the amino acid sequence, their cellular responses vary. IL-17A, IL-17C, and IL-17F usually trigger host defense response and promote autoimmune inflammatory response, whereas IL-25 (IL17E) induces Th2 polarization with allergic response [10]. In recent studies, IL-25 has been shown to present anti-inflammatory response in RA by reducing Th17 differentiation and IL-17-mediated inflammation [11, 12]. The aforementioned findings support an antiinflammatory role of IL-25 in RA.

In this study, we investigated the expression levels of IL-22 and IL-25 in patients with RA and studied the role of IL-25 in IL-22-induced osteoclastogenesis. Furthermore, the underlying intracellular mechanisms of IL-25 with respect to osteoclastogenesis were evaluated in RA synoviocytes.

\section{Methods}

\section{Patients}

Samples of synovial tissue were isolated from 5 patients with RA (mean age $55.2 \pm 3.8$ years; range $44-64$ years) and 5 with osteoarthritis (OA) patients (mean age $57.8 \pm 3.0$ years; range $50-68$ years), who were undergoing total knee replacement surgery. Synovial fluid was obtained from patients with RA $(N=29)$, who fulfilled the revised criteria of the American College of Rheumatology, 1987 (formerly the American Rheumatism Association), and from patients who had symptomatic knee OA $(N=29)$. Additionally, a total 25 serum of healthy control were included. Informed consent was obtained from all patients, and the experimental protocol was approved by the Konkuk University School of Medicine Human Research Ethics Committee (KUH1010186).

\section{Isolation of FLS}

FLSs were isolated by enzymatic digestion of synovial tissues obtained from patients with RA, who were undergoing total knee replacement surgery, as described previously [13].

\section{Reagents}

IL-22, IL-25, RANKL, and macrophage colonystimulating factor (M-CSF) were obtained from R\&D Systems (Minneapolis, MN, USA).

\section{Enzyme-linked immunosorbent assay (ELISA) of IL-22, IL- 25, and SRANKL}

In brief, a 96-well plate (Nunc, Roskilde, Denmark) was coated with $4 \mu \mathrm{g} / \mathrm{ml}$ monoclonal antibodies against IL22, IL-25, IL-1 $\beta$, TNF- $\alpha$, IL-6, IL-4, IL-13, and sRANKL (R\&D Systems, Minneapolis, MN, USA) at $4{ }^{\circ} \mathrm{C}$ overnight. After blocking with phosphate-buffered saline/1\% bovine serum albumin (BSA)/0.05\% Tween 20 for $2 \mathrm{~h}$ at room temperature $\left(22-25^{\circ} \mathrm{C}\right)$, the test samples and the standard recombinant IL-22, IL-25, IL-1 $\beta$, TNF- $\alpha$, IL-6, IL-4, IL-13, and sRANKL (R\&D Systems) were added to the 96-well plate and incubated at room temperature for 
another $2 \mathrm{~h}$. The plates were washed four times with phosphate-buffered saline/Tween 20, and then incubated with $500 \mathrm{ng} / \mathrm{ml}$ biotinylated mouse monoclonal antibodies against IL-22, IL-25, IL-1 $\beta$, TNF- $\alpha$, IL-6, IL-4, IL13 , and sRANKL (R\&D Systems) for $2 \mathrm{~h}$ at room temperature. After washing, streptavidin-alkaline phosphate-horseradish peroxidase conjugate (Sigma, St Louis, MA, USA) was incubated for $2 \mathrm{~h}$, followed by another wash, and incubated with $1 \mathrm{mg} / \mathrm{ml} p$-nitrophenyl phosphate (Sigma) dissolved in diethanolamine (Sigma) to develop the color reaction. The reaction was stopped by the addition of $1 \mathrm{M} \mathrm{NaOH}$, and optical density of each well was measured at $405 \mathrm{~nm}$. The lower limit of IL-22, IL-25, IL-1 $\beta$, TNF- $\alpha$, IL-6, IL-4, IL-13, and sRANKL detection was $10 \mathrm{pg} / \mathrm{ml}$. Recombinant human IL-22, IL-25, IL-1 $\beta$, TNF- $\alpha$, IL-6, IL-4, IL-13, and sRANKL, diluted in culture medium, were used as calibration standards, ranging from 10 to $2000 \mathrm{pg} / \mathrm{ml}$. A standard curve was drawn by plotting optical density against $\log$ of the concentration of recombinant cytokines, and the curve was used for determining IL-22, IL25 , IL-1 $\beta$, TNF- $\alpha$, IL-6, IL-4, IL-13, and sRANKL concentrations in test samples.

\section{Immunohistochemistry of RA synovium}

Immunohistochemical staining for IL-25 was performed with sections of synovium. Briefly, synovial samples were obtained from patients with RA and OA, fixed with $4 \%$ paraformaldehyde solution overnight at $4{ }^{\circ} \mathrm{C}$, dehydrated with alcohol, washed, embedded in paraffin, and sectioned into $7-\mu \mathrm{m}$-thick slices. Sections were depleted of endogenous peroxidase activity by adding methanolic $\mathrm{H}_{2} \mathrm{O}_{2}$ and blocked with normal serum for $30 \mathrm{~min}$. After overnight incubation with polyclonal anti-human IL-25 antibody (Santa Cruz Biotechnology, Santa Cruz, CA, USA) at $4{ }^{\circ} \mathrm{C}$, the samples were incubated with a secondary antibody, biotinylated anti-rabbit IgG, for $20 \mathrm{~min}$, and then with streptavidin-peroxidase complex (Vector Laboratories, Peterborough, UK) for $1 \mathrm{~h}$, followed by a 5-min incubation with 3,3'-diaminobenzidine (Dako, Glostrup, Denmark). The sections were counterstained with hematoxylin. Samples were finally photographed using an Olympus (Tokyo, Japan) photomicroscope. The area of IL- $25^{+}$cell from samples was measured in samples using ImageJ software.

\section{Expression of RANKL mRNA by real-time polymerase chain reaction (PCR)}

FLSs were stimulated with various concentrations of IL-22 $(0,1,10 \mathrm{ng} / \mathrm{ml})$. They were incubated in the presence or absence of IL-25 $(10,50,100 \mathrm{ng} / \mathrm{ml})$ for $4 \mathrm{~h}$ before the addition of IL-22. After $72 \mathrm{~h}$, mRNA levels were measured using real-time PCR, as reported previously [14].

\section{Western blot analysis}

FLSs and PBMC were incubated with IL-22 in the presence or absence of IL-25. After incubation for $1 \mathrm{~h}$, whole-cell lysates were prepared from approximately $2 \times$ $10^{5}$ cells, by homogenization in the lysis buffer, and then centrifuged at $14,000 \mathrm{rpm}$ for $15 \mathrm{~min}$. Protein concentration in the supernatant was determined using the Bradford method (Bio-Rad, Hercules, CA, USA). Protein samples were separated by $10 \%$ sodium dodecyl sulfatepolyacrylamide electrophoresis (SDS-PAGE) and transferred to a nitrocellulose membrane (Amersham Pharmacia Biotech, Uppsala, Sweden). For western blotting, the membrane was pre-incubated with $0.5 \%$ skim milk in $0.1 \%$ Tween 20 and Tris-buffered saline (TTBS) at room temperature for $2 \mathrm{~h}$. The primary antibodies to phospho-stat3, stat3, phospho-p38, p38, phospho-IкB- $\alpha$, and IкB- $\alpha$ (Cell Signaling Technology Inc., Danvers, MA, USA), diluted 1:1000 in 5\% BSA-0.1\% Tween 20/ TBS, were added and incubated overnight at $4{ }^{\circ} \mathrm{C}$. The membrane was washed 4 times with TTBS, followed by the addition of horseradish peroxidase-conjugated secondary antibody and incubation for an hour at room temperature. After TTBS washing, hybridized bands were detected using the ECL detection kit and Hyperfilm-ECL reagents (Amersham Pharmacia).

\section{Osteoclast formation}

PBMCs were collected from healthy blood by density gradient separation, and monocytes (osteoclast precursors: pre-OC) were prepared from them. Human monocytes were seeded in 48 -well plates at $5 \times 10^{4}$ cells/well with $1 \mathrm{ml}$ of medium. Monocytes were cultured under $\alpha$-minimum essential medium, $10 \%$ heat-inactivated FBS, and $25 \mathrm{ng} / \mathrm{ml}$ of recombinant human M-CSF (rhMCSF) for 3 weeks. Then, monocytes were pre-treated with IL-25 and for $4 \mathrm{~h}$, following which they were added to each well along with IL-22. RANKL was used as the positive control. On day 21 , tartrate-resistant acid phosphatase (TRAP)-positive cells were identified, as described previously [14].

\section{Statistical analysis}

All data are expressed as the mean \pm standard error of the mean (SEM). Statistical analysis was performed using one-way analysis of variance and Bonferroni's multiple comparisons test. Spearman's correlated test was used to seek correlation between cytokine levels. In all analyses, $P<0.05$ indicated statistical significance.

\section{Results}

Synovial and serum levels of IL-25 and correlation with IL22 in patients with RA

Expression of IL-25 in synovial fluid and serum was measured and compared across RA, OA, and healthy 

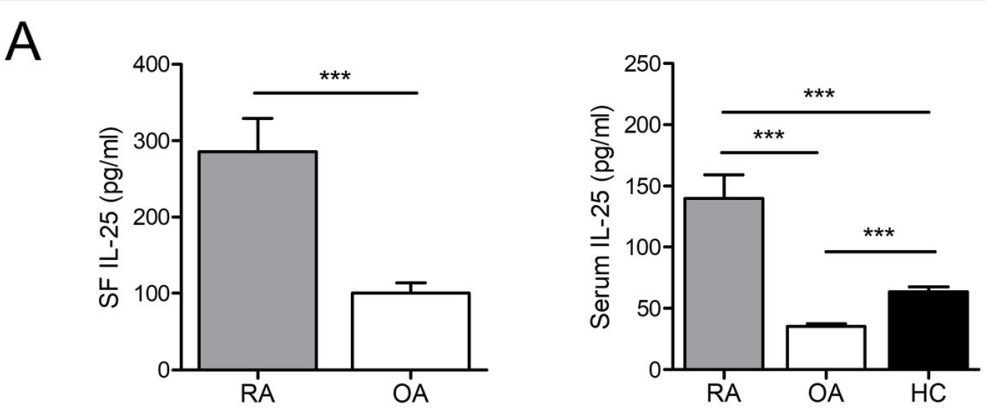

B
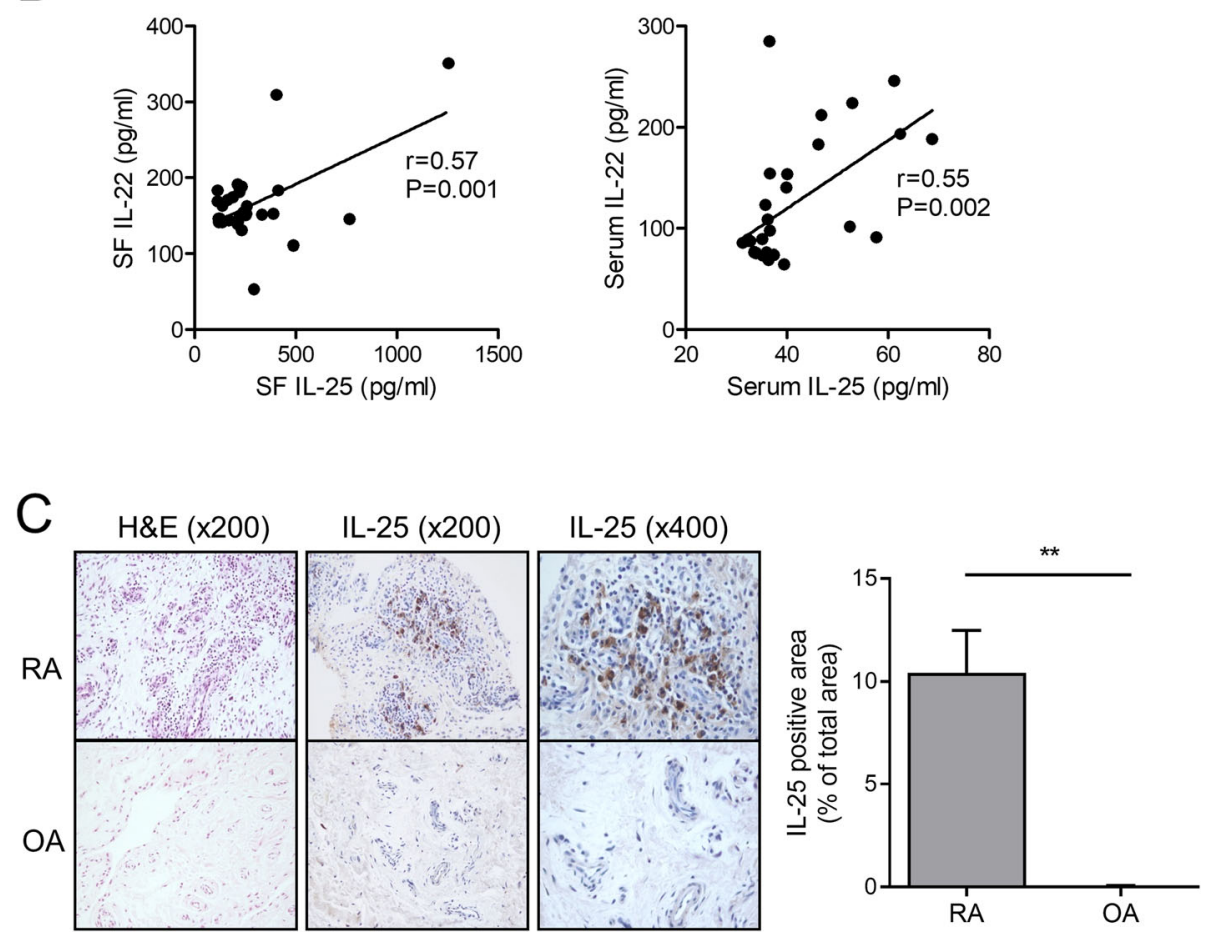

Fig. $1 \mathrm{LL}-22$ and IL-25 expression in serum, synovial fluid, and synovial tissue from patients with rheumatoid arthritis (RA). a Concentrations of IL25 were determined in the synovial fluid and serum of RA and OA, and healthy control subjects. $\mathbf{b}$ Correlations between the IL-22 and IL-25 concentrations were assessed in the synovial fluid and serum of patients with RA. c Expression of IL-25 was detected in the synovium of patients with RA and OA patients using immunohistochemical staining, with hematoxylin and eosin (H\&E) counterstaining. Original magnification $\times 400 .{ }^{* * *} P<0.001$

control samples (synovial fluid was compared only between patients with RA and OA). Detailed clinical information of RA patients, OA patients, and healthy control was summarized in supplementary Table 1 . The level of IL-25 in synovial fluid was significantly higher in RA than in OA cases, and serum IL-25 level was significantly higher in RA than in OA or healthy control samples (Fig. 1a). IL-22 is known to be increased in the serum and synovium of RA cases [7, 8, 15]; we measured the levels of IL-22 and IL-25 in both serum and synovial fluid of patients with RA to reveal whether IL-22 and IL25 levels are correlated. Serum $(N=29)$ and synovial fluid $(N=29)$ levels of IL-25 showed significant correlation with those of IL-22 (Fig. 1b). Synovial tissue stained against IL-25 presented more number of IL-25expressing cells in RA than in OA synovium (Fig. 1c). Other cytokines including pro-inflammatory cytokines (TNF- $\alpha$, IL-1 $\beta$, and IL-6) and anti-inflammatory cytokines (IL-4 and IL-13) were measured in serum and synovial fluid (supplementary Fig. 1). None of them between IL-25 and TNF- $\alpha /$ IL-1 $\beta /$ IL- 6 , neither between IL-22 and IL-4/IL-13 showed significant correlation (supplementary Fig. 2 and 3). Furthermore, the levels of IL-1 $\beta$, TNF- $\alpha$, IL-6, IL-4, and IL-13 did not change by IL-22 or IL-25 stimulation in RA-FLS (supplementary Fig. 4). 


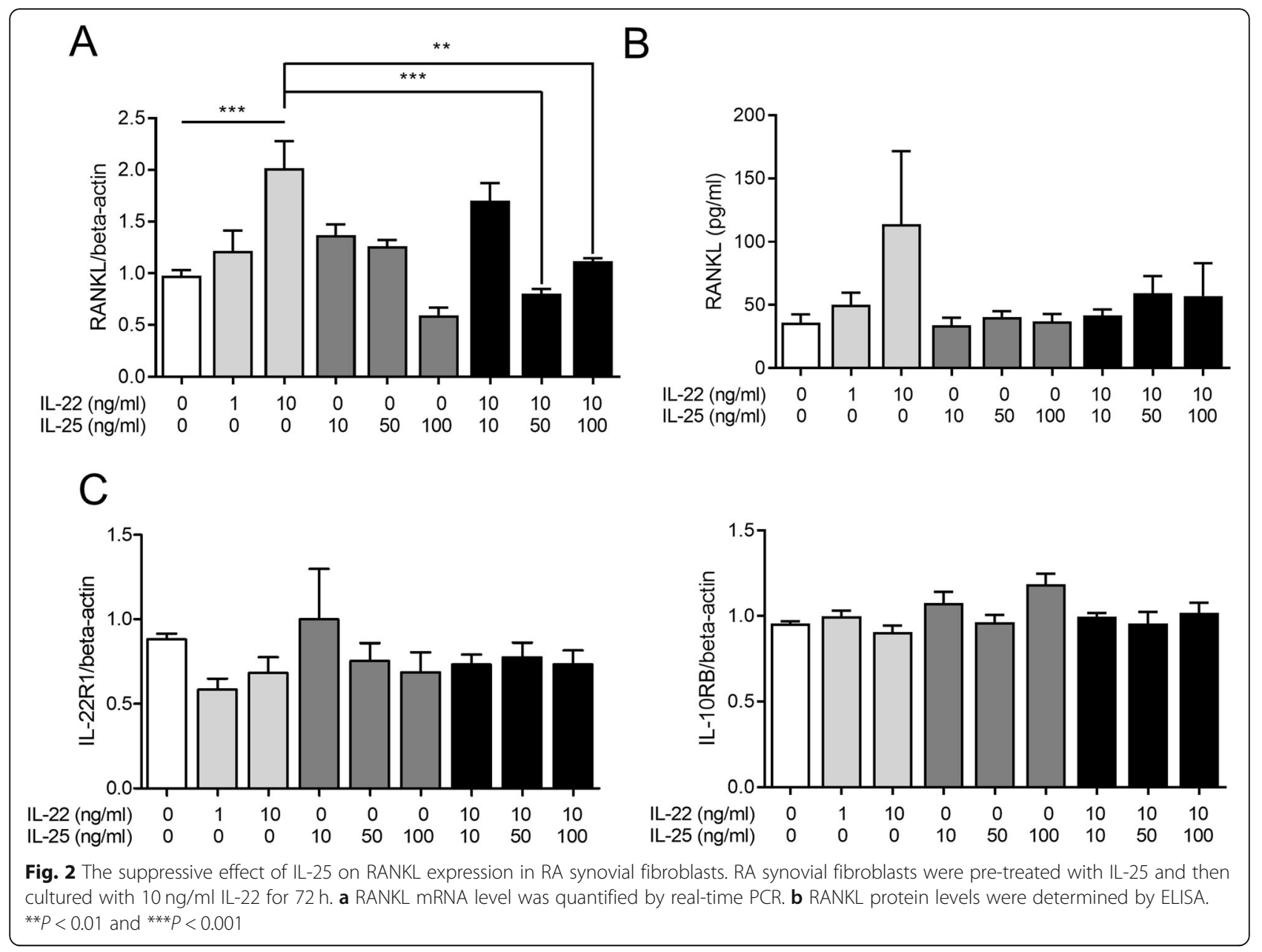

Suppression of IL-22-mediated RANKL expression in FLS after IL-25 pre-treatment

Both mRNA and protein levels of RANKL in FLSs were measured by real-time PCR and ELISA, respectively. IL22 upregulated RANKL mRNA expression in a dosedependent manner, and pre-treatment with IL-25 significantly suppressed the IL-22-induced overexpression of RANKL (Fig. 2a). The protein levels of RANKL only tended to increase following IL-22 induction and decreased upon IL-25 pre-treatment (Fig. 2b). However, addition of IL-25 did not change mRNA levels of IL-22 receptors, $I L-22 R 1$ and $I L-10 R B$ (Fig. 2c), which indicates that suppressive role of IL-25 on RANKL expression was independent with expression levels of IL-22 receptor. Co-stimulation of IL-22 and IL-25 (not IL-25 pretreatment for $4 \mathrm{~h}$ ) showed similar results (supplementary Fig. 5).

Intracellular signaling pathway involved in the regulatory function of IL-25 in osteoclastogenesis

IL-22-induced osteoclastogenesis has been previously shown to be mediated through the p38 MAPK/NF-kB or
STAT-3 signaling pathway [8]. IL-22 stimulation alone promoted phosphorylation of STAT3 (Tyr705) and p38, whereas IL-25 pre-treatment downregulated the IL-22induced phosphorylation of STAT3 (Tyr705, Ser727), p38, and IкB- $\alpha$ in RA-FLS (Fig. 3a). Therefore, the ratio of total to phosphorylated forms of STAT3, p38, and IкB- $\alpha$ significantly decreased (Fig. 3b, raw western blot data in supplementary Fig. 6). The IL-25 stimulation without IL-22 on RA-FLS only suppressed expression level of phosphorylated p38 (supplementary Fig. 7). Pretreatment of IL-25 with IL-22 stimulation in PBMC suppressed expression of phosphorylated STAT3, p38, and I $\mathrm{B}-\alpha$ (Fig. 4, raw western blot data in supplementary Fig. 8).

\section{Regulatory effect of IL-25 in osteoclast differentiation from PBMCs}

Human PBMCs were cultured under stimulation by IL22 or RANKL with M-CSF. IL-22 and RANKL effectively induced the differentiation of PBMCs into $\mathrm{TRAP}^{+}$multinucleated osteoclasts (Figs. 5a and 6a). IL-25 suppressed osteoclast differentiation in a dose-dependent manner, 


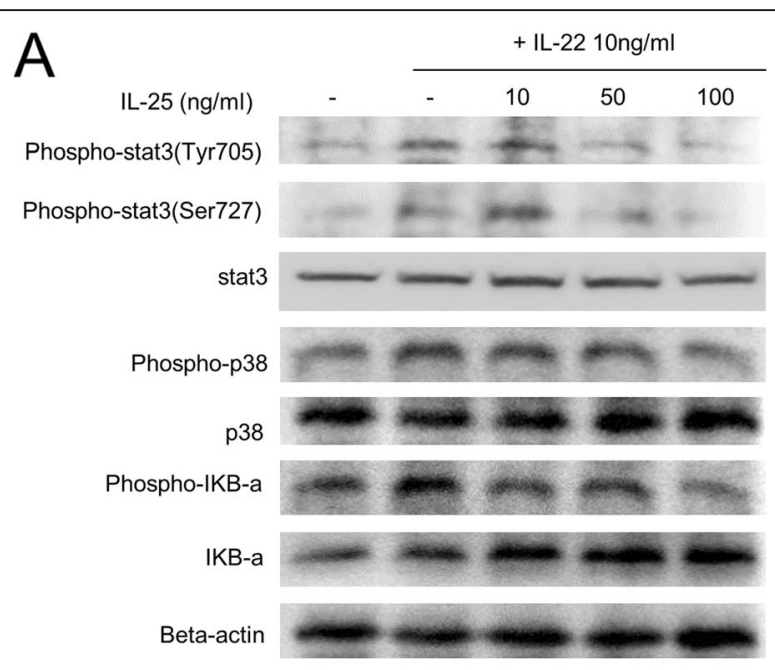

B
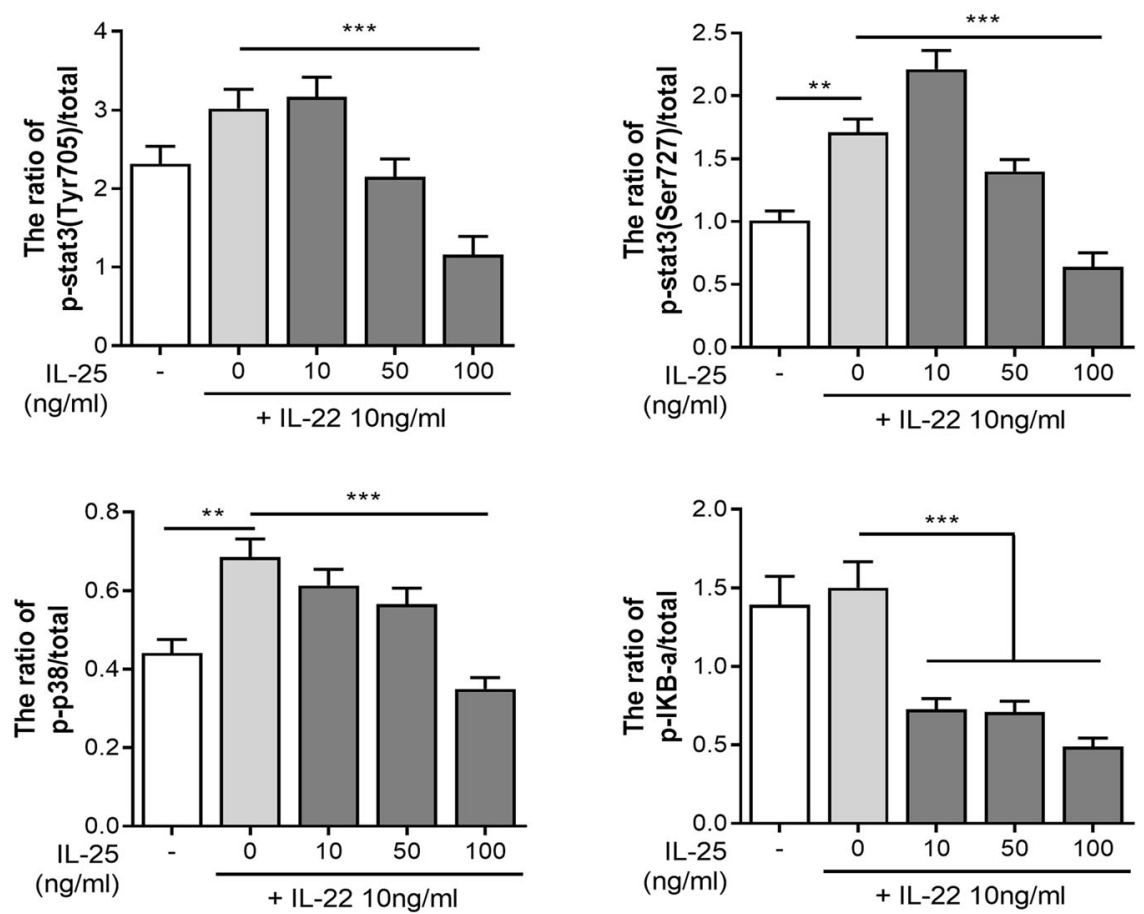

Fig. 3 Intracellular signaling pathways involving in the regulation of IL-25 in IL-22-induced RANKL expression in RA synovial fibroblasts. a Immunoblotting of $p$-stat3, stat3, p-P38, P38, p-IKB-a, IKB-a, and beta-actin in the RA synovial fibroblasts pre-treated with IL-25 (10, 50, 100 ng/ml) and then cultured under IL-22 for $1 \mathrm{~h}$. $\mathbf{b}$ Data were normalized to beta-actin and reported in relative expression units. Bars show the mean \pm SEM of 3 independent experiments. ${ }^{*} P<0.05,{ }^{* *} P<0.01$, and ${ }^{* * *} P<0.001$

in both IL-22- and RANKL-stimulated PBMCs (Figs. 5a and 6a). To investigate the expression of osteoclast-related markers, we evaluated the mRNA levels of TRAP, NFATc1, cathepsin K, OC-STAMP, and ATP6v0d2. Stimulation with either IL-22 or RANKL with M-CSF overexpressed the aforementioned osteoclast-related markers (Figs. 5b and 6b). Co-administration of IL-25, however, lowered the expression levels of all osteoclast markers in IL-22 stimulation (Fig. 5b). Additionally, IL-25 suppressed the osteoclast markers, TRAP, cathepsin K, OC-STAMP, and ATP6v0d2, in RANKL-stimulated conditions (Fig. 6b). NFATc1 expression was significantly suppressed with IL-25-only stimulation at a concentration of $100 \mathrm{ng} / \mathrm{ml}$ (Fig. 6b).

\section{Discussion}

IL-22 belongs to the IL-10 family and shares about 25\% structural homology with the latter [16]. It can evoke 


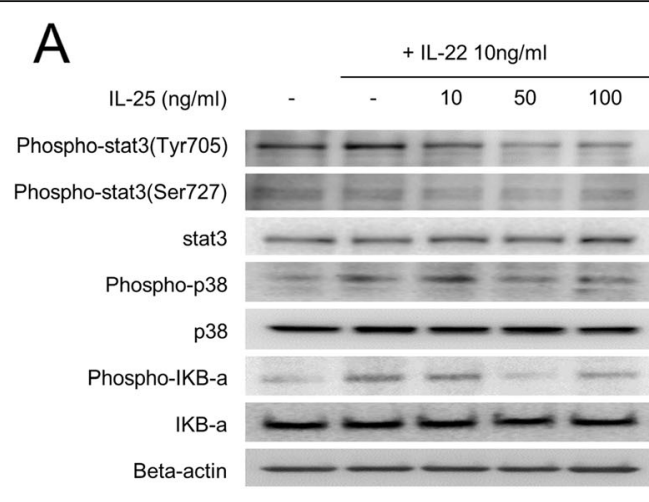

\section{B}
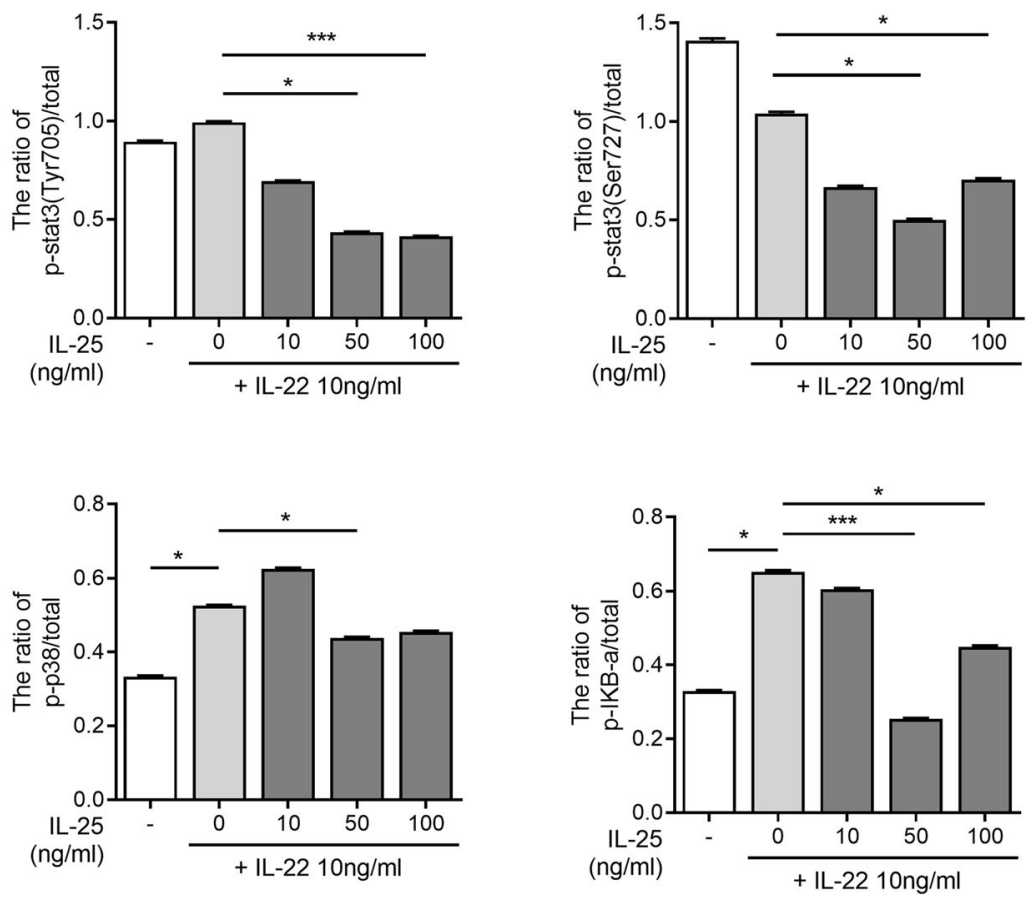

Fig. 4 Intracellular signaling pathways involving in the regulation of IL-25 in IL-22-induced RANKL expression in PBMC. a Immunoblotting of $p$ stat3, stat3, p-P38, P38, p-|KB-a, IKB-a, and beta-actin in the PBMC pre-treated with IL-25 (10,50, $100 \mathrm{ng} / \mathrm{ml})$ and then cultured under IL-22 for $1 \mathrm{~h}$. b Data were normalized to beta-actin and reported in relative expression units. Bars show the mean \pm SEM of 3 independent experiments. ${ }^{* * *} P<0.001$

both tissue repair/host defense and inflammatory immune response depending on the organs and diseases [17]. In addition to its diverse functions, it mainly acts on non-hematopoietic cells, such as epithelial cells and fibroblasts, and promotes epithelial cell regeneration. RA synovium has been reported to present high levels of IL22 expression and is implicated in RA pathogenesis via FLS proliferation and production of monocyte chemoattractant protein 1 (MCP-1) [15]. IL-22 can be expressed by many immune cells, and among the $\mathrm{CD} 4^{+}$ $\mathrm{T}$ cells, Th22 produces over $50 \%$ of IL-22 in the peripheral blood [18]. Elevation of IL-22 and Th22 population in patients with RA has been adequately reported, and plasma IL-22 and Th22 levels have shown correlation with RA disease activity (DAS-28) [19-21]. Elevated IL22 levels in plasma can predict future bone erosion in RA [22], and IL-22 produced by natural killer (NK) cells can induce FLS proliferation [9]. Furthermore, IL-22 has been reported to promote osteoclastogenesis via the $\mathrm{p} 38$ MAPK/NF- $\mathrm{KB}$ and JAK2/STAT-3 signaling pathways [8]; Th22 cells have been shown to play a crucial role in osteoclastogenesis by producing IL-22 [23]. These findings collectively support the pathological roles of IL-22 in RA pathogenesis and progression. In the current study, besides re-confirming the pathological role of IL22 in osteoclastogenesis, suppression of IL-22-induced osteoclastogenesis by IL- 25 has been revealed for the first time. 

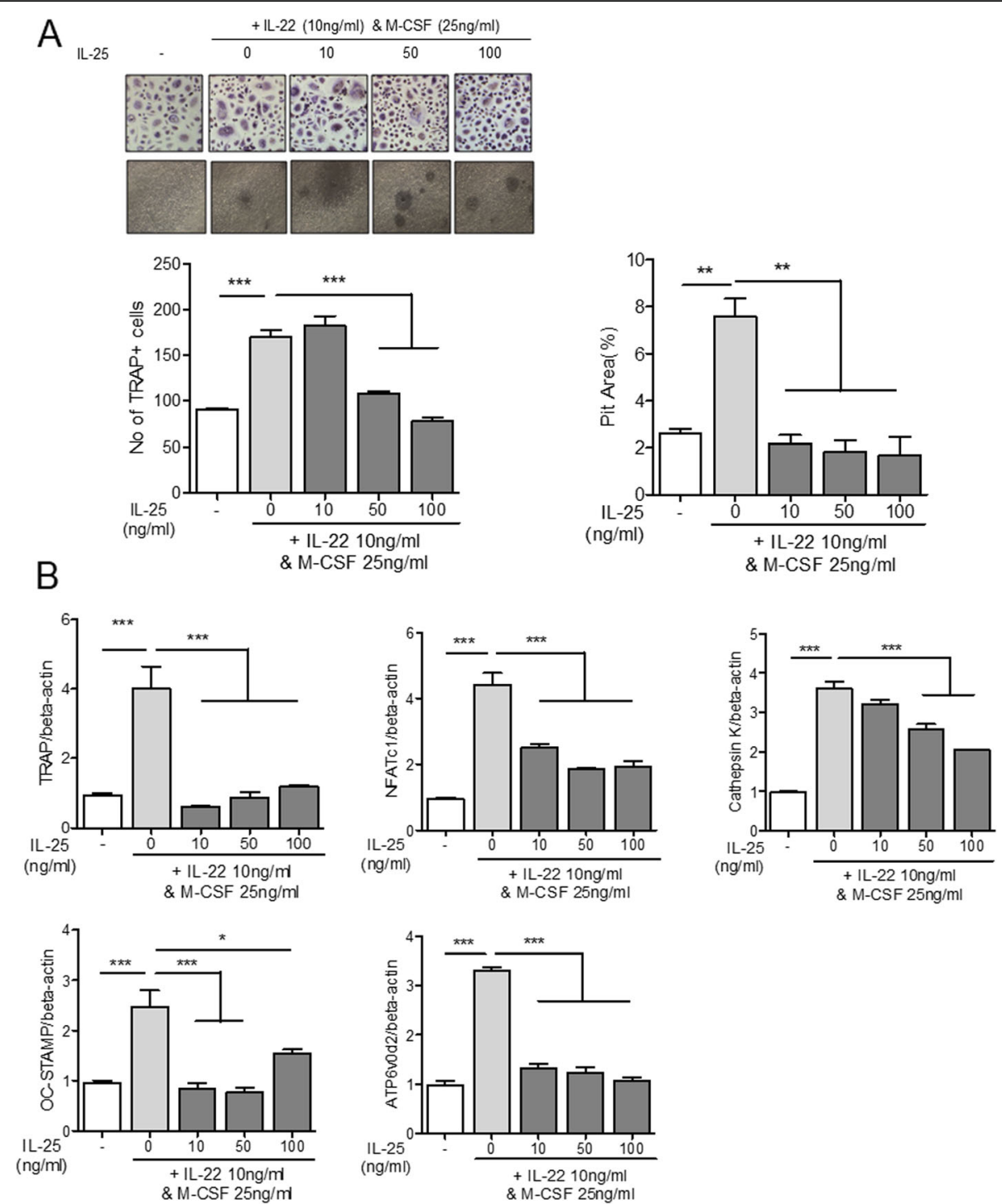

Fig. 5 The effect of IL-25 in IL-22-induced osteoclast differentiation from peripheral blood monocytes. CD14 ${ }^{+}$monocytes were pre-treated with IL-25 $(0,10,50,100 \mathrm{ng} / \mathrm{ml})$ for $4 \mathrm{~h}$, and then cultured with $25 \mathrm{ng} / \mathrm{ml}$ of M-CSF and $10 \mathrm{ng} / \mathrm{ml} \mathrm{IL-22.} \mathrm{a} \mathrm{TRAP}{ }^{+}$multinucleated cell count and pit area were measured. $\mathbf{b}$ The gene expression of TRAP, NFATc1, cathepsin K, OC-STAMP, and ATP6VOd2 from differentiated osteoclasts was measured by real-time PCR. Data were normalized to beta-actin and reported in relative expression units. ${ }^{*} P<0.05,{ }^{* *} P<0.01$, and ${ }^{* * *} P<0.001$

IL-25, also called IL-17E, binds to the heterodimeric receptor composed of IL-17RA and IL17RB [10]. It is known to induce Th2 dominant response and cause allergic reaction [24]. Helminth-induced Th2 immune response can suppress inflammatory arthritis and bone loss via the IL-4/IL-13-induced STAT6 pathway [25]. Similarly, IL-25 can attenuate Th17 differentiation in RA in an IL-13-mediated manner [11]. IL-25 has been reported to be produced by synoviocytes in delayed phase after stimulation with IL-17A and TNF- $\alpha$ [12]. Such delayed-phase generation of IL-25 suppresses the production of pro-inflammatory cytokines, IL-6 and IL-17A, in RA synoviocytes [12]. IL-17RB is expressed in various cells, such as NKT, myeloid, Th9, mast, and dendritic cells, as well as basophils, eosinophils, and macrophages [24]. Osteoclast precursor cells, monocytes, have been previously shown to express IL-17RB and IL-17RA in a mouse model [26], as well as in human synoviocytes [12]. In the present study, the novel antagonistic function of IL- 25 on osteoclastogenesis induced by IL- 22 has been presented.

Elevated plasma and synovial levels of IL-22 and IL-25 in RA have been revealed in previous studies [7, 11, 15, 21, 22]. The regulatory role of IL-25 in RA has been introduced as antagonistic to IL-17A, at a delayed time point when stimulated by TNF- $\alpha$ and IL-17A, in RA [12]. Here, we showed the correlation of IL-22 and IL-25 in the plasma and synovial fluid samples of patients with RA. Considering the 

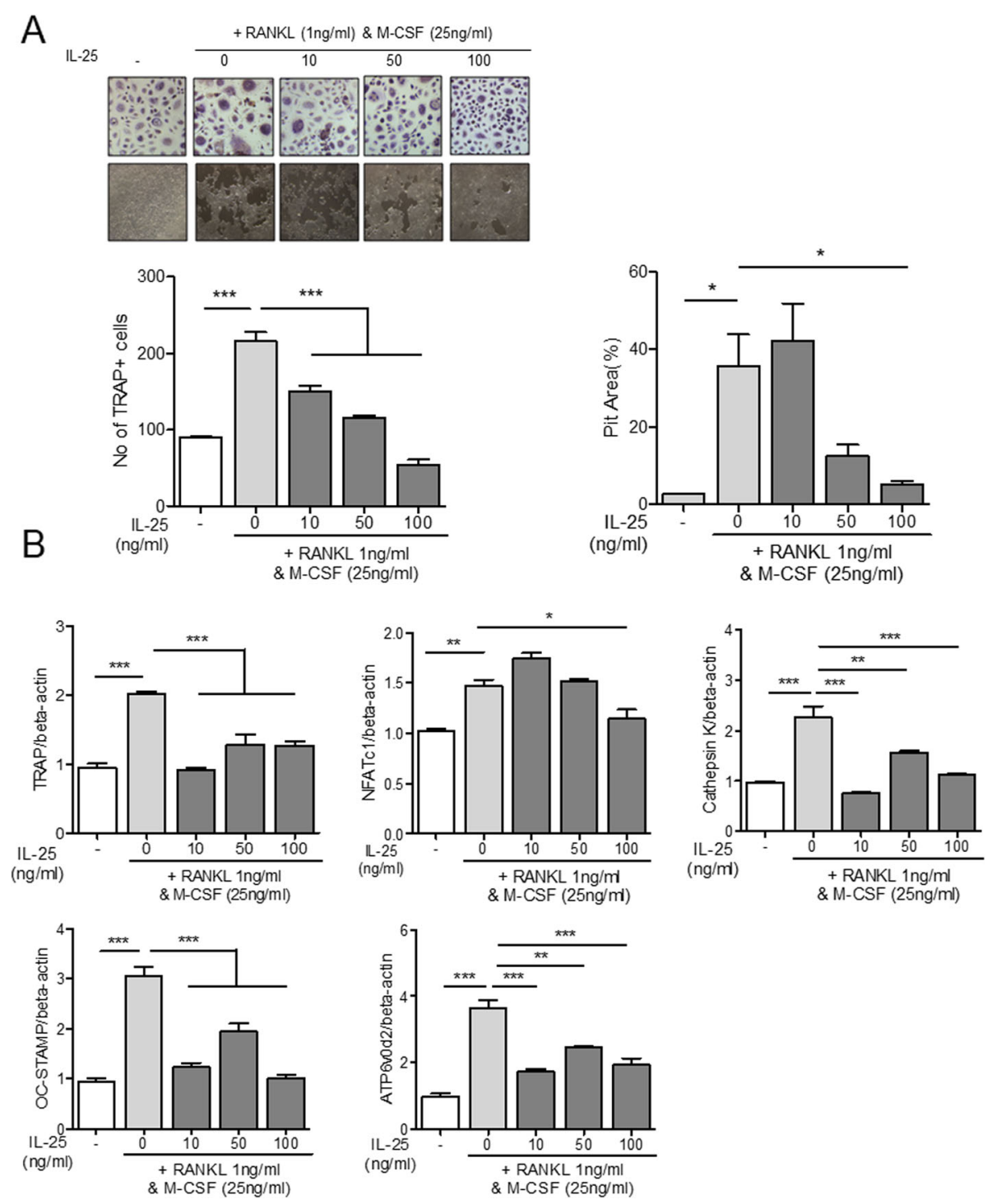

Fig. 6 The effect of IL-25 in RANKL-induced osteoclast differentiation from peripheral blood monocytes. CD14 ${ }^{+}$monocytes were pre-treated with IL-25 $(0,10,50,100 \mathrm{ng} / \mathrm{ml})$ for $4 \mathrm{~h}$, and then cultured with $25 \mathrm{ng} / \mathrm{ml}$ of M-CSF and $1 \mathrm{ng} / \mathrm{ml}$ RANKL. a TRAP ${ }^{+}$multinucleated cell count and pit area were measured. $\mathbf{b}$ The gene expression of TRAP, NFATc1, cathepsin K, OC-STAMP, and ATP6VOd2 from differentiated osteoclasts was measured by real-time PCR. Data were normalized to beta-actin and reported in relative expression units. ${ }^{*} P<0.05,{ }^{* *} P<0.01$, and ${ }^{* *} P<0.001$

regulatory function of IL-25 and the aforementioned correlation with IL-22, IL-25 might be upregulated in response to pathogenic cytokines, such as TNF- $\alpha$, IL-17A, and IL-22, and antagonize the functions of the pro-inflammatory cytokines. Furthermore, IL-25 is produced by synoviocytes [12], cornerstone component of pannus, and close proximity of synoviocytes with osteoclast precursors makes IL-25 an attractive treatment target.

\section{Conclusions}

In conclusion, the present study showed the suppressive role of IL-25 in osteoclastogenesis in case of RA. Since prevention of bone destruction and bone loss in RA is one of the major treatment targets, upregulation of IL25 could serve as a novel therapeutic approach for treating RA.

\section{Supplementary information}

Supplementary information accompanies this paper at https://doi.org/10. 1186/s13075-020-02315-8.

Additional file 1: Supplementary Table 1. Characteristics of rheumatoid, osteoarthritis patients, and healthy control.

Additional file 2: Supplementary Figure 1. Serum and synovial fluid levels of IL-22, IL25, IL-13, TNF-a, IL-6, IL-4, and IL-13 in RA, OA, and healthy control. 
Additional file 3: Supplementary Figure 2. Correlation between IL-25 and IL-1 $\beta$ / TNF- $\alpha$ / IL-6 in serum and synovial fluid of RA patients.

Additional file 4: Supplementary Figure 3. Correlation between IL-22 and IL-4 / IL-13 in serum and synovial fluid of RA patients.

Additional file 5: Supplementary Figure 4. Serum levels of IL-1 $\beta$, TNF-a, IL-6, IL-4, and IL-13 after stimulation with IL-22 and IL-25 in RA-FLS. Additional file 6: Supplementary Figure 5. The suppressive effect of IL-25 on RANKL expression in RA synovial fibroblasts (IL-22 and IL-25 costimulation condition). (A) RANKL mRNA level was quantified by real-time $P C R$. (B) RANKL protein level were determined by ELISA.

Additional file 7: Supplementary Figure 6. Raw western blot data of Fig. 3 (IL-25 pre-treatment with IL-22 stimulation on RA synovial fibroblast)

Additional file 8: Supplementary Figure 7-1. Effects of IL-25 stimulation without IL-22 on RA synovial fibroblasts (A) Immunoblotting of $p$ stat3, stat3, p-P38, P38, p-IKB-a, IKB-a, and beta-actin in the RA synovial fibroblasts with IL-25 single stimulation (10, 50, $100 \mathrm{ng} / \mathrm{ml}$ ) for $4 \mathrm{hrs}$. (B) Data were normalized to beta actin and reported in relative expression units. Bars show the mean \pm SEM of 3 independent experiments. " $P<$ $0.05,{ }^{* * *} P<0.01$, and ${ }^{* * * *} P<0.001$. Supplementary Figure 7-2 to 5. Raw western blot data (IL-25 single stimulation on RA synovial fibroblast).

Additional file 9: Supplementary Figure 8. Raw western blot data of Fig. 4 (IL-25 pre-treatment with IL-22 stimulation on PBMC).

\section{Abbreviations}

CD: Cluster of differentiation; DMARDs: Disease-modifying antirheumatic drugs; ELISA: Enzyme-linked immunosorbent assay; FLS: Fibroblast-like synoviocyte; IL: Interleukin; OA: Osteoarthritis; PBMC: Peripheral blood mononuclear cell; PCR: Polymerase chain reaction; RA: Rheumatoid arthritis; RANK: Receptor activator of nuclear factor $\mathrm{KB}$; RANKL: Receptor activator of nuclear factor KB ligand; SDS-PAGE: Sodium dodecyl sulfate-polyacrylamide electrophoresis; SEM: Standard error mean; Th: Helper T cell; TNF: Tumor necrosis factor; TRAP: Tartrate-resistant acid phosphatase; TTBS: Tween 20 in Tris-buffered saline

\section{Acknowledgements}

None.

\section{Authors' contributions}

All authors were involved in drafting the article or revising it critically for important intellectual content, and all authors approved the final version to be published. Dr. Kim had full access to all of the data in the study and takes responsibility for the integrity of the data and the accuracy of the data analysis. Study conception and design: H.-K. Min, K.-W. Kim, and H.-R. Kim. Acquisition of data: K.-W. Kim, J.-Y. Won, B.-M. Kim, K.-A. Lee, S.-J. Lee, and H.R. Kim. Analysis and interpretation of data: H.-K. Min, J.-Y. Won, K.-W. Kim, H.R. Kim, and S.-H. Lee.

\section{Funding}

This research was supported by a grant of the Basic Science Research Program through the National Research Foundation of Korea funded by the Ministry of Education, Science and Technology, Republic of Korea (NRF2018R1D1A1A02050982), and the Basic Science Research Program through the National Research Foundation of Korea funded by the Ministry of Science, ICT \& Future Planning (NRF-2018R1A2B2006820).

\section{Availability of data and materials}

The datasets generated and/or analyzed in this study are available from the corresponding author upon reasonable request.

\section{Ethics approval and consent to participate}

Informed consent was obtained from all patients, and the experimental protocol was approved by the Konkuk University School of Medicine Human Research Ethics Committee (KUH1010186).

\section{Consent for publication}

Informed consent was obtained from all patients.

\section{Competing interests}

The authors declare that they have no competing interests related to this manuscript.

\section{Author details}

'Division of Rheumatology, Department of Internal Medicine, Konkuk University Medical Center, Seoul 05030, Republic of Korea. ${ }^{2}$ R\&D Center, Oncolnsight, 1022, Gangnam AceTower, 174-10, Jagok-ro, Gangnam-gu, Seoul 06373, Republic of Korea. 'Laboratory of Stem Cell, NEXEL, Seoul, Republic of Korea. ${ }^{4}$ Division of Rheumatology, Department of Internal Medicine, Soonchunhyang University Hospital, Seoul 04401, Republic of Korea. ${ }^{5}$ Department of Orthopedic Surgery, School of Medicine, Konkuk University, Seoul 05030, Republic of Korea. ${ }^{6}$ Division of Rheumatology, Department of Internal Medicine, Research Institute of Medical Science, School of Medicine, Konkuk University, Seoul 05030, Republic of Korea.

Received: 17 December 2019 Accepted: 11 September 2020

Published online: 23 September 2020

\section{References}

1. Smolen JS, Landewe R, Bijlsma J, Burmester G, Chatzidionysiou K, Dougados M, Nam J, Ramiro S, Voshaar M, van Vollenhoven R, et al. EULAR recommendations for the management of rheumatoid arthritis with synthetic and biological disease-modifying antirheumatic drugs: 2016 update. Ann Rheum Dis. 2017;76(6):960-77.

2. Smolen JS, Aletaha D, Barton A, Burmester GR, Emery P, Firestein GS, Kavanaugh A, McInnes IB, Solomon DH, Strand V, et al. Rheumatoid arthritis. Nat Rev Dis Primers. 2018:4:18001.

3. Takayanagi H. New developments in osteoimmunology. Nat Rev Rheumatol. 2012;8(11):684-9.

4. Aletaha D, Smolen JS. Diagnosis and management of rheumatoid arthritis: a review. JAMA. 2018;320(13):1360-72.

5. Justa S, Zhou X, Sarkar S. Endogenous IL-22 plays a dual role in arthritis: regulation of established arthritis via IFN-gamma responses. PLoS One. 2014; 9(3):e93279.

6. Corneth OB, Reijmers RM, Mus AM, Asmawidjaja PS, van Hamburg JP, Papazian N, Siegers JY, Mourcin F, Amin R, Tarte K, et al. Loss of IL-22 inhibits autoantibody formation in collagen-induced arthritis in mice. Eur $\mathrm{J}$ Immunol. 2016;46(6):1404-14.

7. Zhao L, Jiang Z, Jiang Y, Ma N, Zhang Y, Feng L, Wang K. IL-22+ CD4+ T cells in patients with rheumatoid arthritis. Int J Rheum Dis. 2013;16(5):518-26.

8. Kim KW, Kim HR, Park JY, Park JS, Oh HJ, Woo YJ, Park MK, Cho ML, Lee SH. Interleukin-22 promotes osteoclastogenesis in rheumatoid arthritis through induction of RANKL in human synovial fibroblasts. Arthritis Rheum. 2012; 64(4):1015-23.

9. Zhu J, Jia E, Zhou Y, Xu J, Feng Z, Wang H, Chen X, Li J. Interleukin-22 secreted by NKp44+ natural killer cells promotes proliferation of fibroblastlike synoviocytes in rheumatoid arthritis. Medicine (Baltimore). 2015;94(52): e2137.

10. Gu C, Wu L, Li X. IL-17 family: cytokines, receptors and signaling. Cytokine. 2013;64(2):477-85.

11. Liu D, Cao T, Wang N, Liu C, Ma N, Tu R, Min X. IL-25 attenuates rheumatoid arthritis through suppression of Th17 immune responses in an IL-13dependent manner. Sci Rep. 2016;6:36002.

12. Lavocat F, Ndongo-Thiam N, Miossec $P$. Interleukin-25 produced by synoviocytes has anti-inflammatory effects by acting as a receptor antagonist for interleukin-17A function. Front Immunol. 2017;8:647.

13. Kim HR, Cho ML, Kim KW, Juhn JY, Hwang SY, Yoon CH, Park SH, Lee SH, Kim HY. Up-regulation of IL-23p19 expression in rheumatoid arthritis synovial fibroblasts by IL-17 through PI3-kinase-, NF-kappaB- and p38 MAPKdependent signalling pathways. Rheumatology (Oxford, England). 2007; 46(1):57-64.

14. Kim HR, Kim KW, Kim BM, Lee KA, Lee SH. N-acetyl-I-cysteine controls osteoclastogenesis through regulating Th17 differentiation and RANKL production in rheumatoid arthritis. Korean J Intern Med. 2019:34(1):210-9.

15. Ikeuchi H, Kuroiwa T, Hiramatsu N, Kaneko Y, Hiromura K, Ueki K, Nojima Y. Expression of interleukin-22 in rheumatoid arthritis: potential role as a proinflammatory cytokine. Arthritis Rheum. 2005;52(4):1037-46.

16. Xie MH, Aggarwal S, Ho WH, Foster J, Zhang Z, Stinson J, Wood WI, Goddard AD, Gurney AL. Interleukin (IL)-22, a novel human cytokine that 
signals through the interferon receptor-related proteins CRF2-4 and IL-22R. J Biol Chem. 2000;275(40):31335-9.

17. Dudakov JA, Hanash AM, van den Brink MR. Interleukin-22: immunobiology and pathology. Annu Rev Immunol. 2015;33:747-85.

18. Duhen T, Geiger R, Jarrossay D, Lanzavecchia A, Sallusto F. Production of interleukin 22 but not interleukin 17 by a subset of human skin-homing memory T cells. Nat Immunol. 2009;10(8):857-63.

19. Zhong W, Zhao L, Liu T, Jiang Z. IL-22-producing CD4+T cells in the treatment response of rheumatoid arthritis to combination therapy with methotrexate and leflunomide. Sci Rep. 2017;7:41143.

20. da Rocha LF Jr, Duarte AL, Dantas AT, Mariz HA, Pitta Ida R, Galdino SL, Pitta MG. Increased serum interleukin 22 in patients with rheumatoid arthritis and correlation with disease activity. J Rheumatol. 2012;39(7):1320-5.

21. Zhang L, Li JM, Liu XG, Ma DX, Hu NW, Li YG, Li W, Hu Y, Yu S, Qu X, et al. Elevated Th22 cells correlated with Th17 cells in patients with rheumatoid arthritis. J Clin Immunol. 2011;31(4):606-14.

22. Leipe J, Schramm MA, Grunke M, Baeuerle M, Dechant C, Nigg AP, Witt MN, Vielhauer V, Reindl CS, Schulze-Koops H, et al. Interleukin 22 serum levels are associated with radiographic progression in rheumatoid arthritis. Ann Rheum Dis. 2011;70(8):1453-7.

23. Miyazaki Y, Nakayamada S, Kubo S, Nakano K, Iwata S, Miyagawa I, Ma X, Trimova G, Sakata K, Tanaka Y. Th22 cells promote osteoclast differentiation via production of IL-22 in rheumatoid arthritis. Front Immunol. 2018;9:2901

24. Liu Y, Shao Z, Shangguan G, Bie Q, Zhang B. Biological properties and the role of IL-25 in disease pathogenesis. J Immunol Res. 2018;2018:6519465.

25. Chen Z, Andreev D, Oeser K, Krljanac B, Hueber A, Kleyer A, Voehringer D, Schett $\mathrm{G}$, Bozec A. Th2 and eosinophil responses suppress inflammatory arthritis. Nat Commun. 2016;7:11596.

26. Ge S, Hertel B, Susnik N, Rong S, Dittrich AM, Schmitt R, Haller H, von Vietinghoff S. Interleukin 17 receptor A modulates monocyte subsets and macrophage generation in vivo. PLoS One. 2014;9(1):e85461.

\section{Publisher's Note}

Springer Nature remains neutral with regard to jurisdictional claims in published maps and institutional affiliations.

Ready to submit your research? Choose BMC and benefit from:

- fast, convenient online submission

- thorough peer review by experienced researchers in your field

- rapid publication on acceptance

- support for research data, including large and complex data types

- gold Open Access which fosters wider collaboration and increased citations

- maximum visibility for your research: over $100 \mathrm{M}$ website views per year

At $\mathrm{BMC}$, research is always in progress.

Learn more biomedcentral.com/submissions 